\title{
Perspectives
}

\section{President's Address 2004: "Wearing Two Hats": Morphed Perspectives on Family Quality of Life}

\author{
Ann P. Turnbull, AAMR President 2003-2004
}

In seeking to identify an appropriate topic for my presidential address, I concluded that I would focus on what I think is my rather unique contribution to the developmental disabilities field: a morphed perspective, namely, wearing two hats-professional and family. As I have reflected on the process of wearing two hats, I realize that I have ended up with a single hat, one-a morphed one-that combines my professional and family perspectives in ways that create a new framework for my thinking, research, and teaching. In this paper I identify how my morphed perspective has influenced my professional career and, especially, how it has provided insights into my current professional goal, which is enhancing family quality of life.

For the last 25 years, I have been on the faculty at the University of Kansas. Currently, I am a professor in the Department of Special Education and co-director of the Beach Center on Disability with my husband and former AAMR president, Rud Turnbull.

\section{Wearing My Professional Hat}

Having majored in special education as an undergraduate at the University of Georgia, I started my career as a teacher of students with mild mental retardation at the elementary school level. After completing my master's degree at Auburn University in the summers and at night while I taught, I worked for a short time at Partlow State School and Hospital in Tuscaloosa, Alabama, which several years later was the first right-to-treatment case, Wyatt v. Stickney. Pursuing my own deinstitutionalization, I returned to graduate school at the University of Alabama to earn my doctorate in special education. Soon thereafter, I took a position at the University of North Carolina at Chapel Hill teaching in the School of Education and serving as the special education director at the University Centers for Excellence It was there that I met Rud at a meeting of The Arc of Douglas County. He was the president of that organization and the father of a 7year-old son, JT, who had been identified as having mental retardation. We were married the following year, and we both worked at the University of North Carolina at Chapel Hill for the following 6 years. In 1980, we moved to Lawrence, Kansas, to work at the University of Kansas. We have been co-directing the Beach Center on Disability for the last 16 years. We also are professors in the Department of Special Education, which has, over the years, been ranked consistently as one of the top doctoral programs in special education in the United States.

\section{Wearing My Family Hat}

When Rud and I married, JT was living in a group home in Massachusetts. Rud and his former wife had made that choice reluctantly. So several months after Rud and I married, we went to Massachusetts to bring JT home to live with us, his new family. During the next 4 years, his two younger sisters, Amy and Kate, were born. I am reminded of what Dick Schiefelbusch, pioneer in the developmental disabilities field, shared with me many years ago: People have their greatest chance to achieve wisdom from the lessons they learn from their children rather than from their professional endeavors. Over the years, I have come to agree with Dick. Rud and I both chronicled some of our early family experiences in our book Parents Speak Out. First published in 1978, the book was a compilation of essays written by parents who also had professional roles in the field. All of these authors wore two hats, and their dual perspectives were the focus of the book. Seven years later we published a second edition, Parents Speak Out: Then and Now, to provide an update of the families. As I recently 
reread those essays, one written when JT was 10 (3 years into the life of our family) and the other written when he was 17 (10 years into our life), I marvel at the lessons learned about the whole disability experience. As I wrote in my first essay in Parents Speak Out, I entered the experience of parenthood with smugness - even arrogance. I had three degrees in special education with an emphasis in mental retardation, several years of teaching experience, and a special education position on the faculty at a research university. I mistakenly thought I was exceedingly well-prepared. Quoting from Parents Speak Out, I admitted:

For one who thought she knew a lot, the last three years have, indeed, been a humbling experience. The 24 -hour reality test has challenges far greater than any examination I ever took while earning my three degrees. In fact, the three degrees may have been more a hindrance than a help in meeting my new parental responsibilities. I had always been taught to be objective and to consider the facts of the situation. All of a sudden, I had an ache in my heart, a knot in my stomach, and tears welling in my eyes. It did not take long for it to dawn on me. . I was in for a startling experience. (Turnbull, 1985, pp. 128-129)

JT is now 37 and is the fortunate recipient of individualized funding (which I describe later), that enables him to live in his own home and to be fully included in our community. He has worked as a clerical aide at the University of Kansas for the last 15 years and has an extensive and rich network of co-worker friends and reliable allies. Over the years JT has acquired the diagnoses of autism and rapid cycling bipolar disorder, in addition to his early diagnosis of mental retardation; both his abilities and disabilities are significant. Yet, life has never been so good for him. Honestly, when I think it cannot get any better, it continues to do so. I am sure my imagination is inadequate to envision the wonderful things that lie ahead for JT in the future.

Our second child, Amy, is 29 and has recently moved from Ann Arbor, Michigan, to Chicago. Amy has a master's degree in social work. In Ann Arbor she was the associate director of a housing agency for individuals with low income and disabilities, a position she now holds in Chicago. We are thrilled that she and her husband, Rahul, are expecting our first grandchild. Our youngest child, Kate, is 26-years-old and a professional actress in New York City_after a double major in Theater and American Studies at the University of Kansas. One of our greatest joys is watching her perform.

Rud and I are currently empty-nesters, except on Sundays when JT comes home for the day and night. On Monday mornings we all go out to breakfast at JT's favorite restaurant, where he is such a "regular" that every staff member and customer eagerly reciprocate and even initiate his unique handshake (somewhat similar to a secret fraternity handshake).

\section{Evolution of Morphed Perspectives}

In an evolutionary way over the years, it is clear to me that my family and professional hats have morphed. My professional priorities are clearly affected by my family experiences and vice versa. There were times early in my career when I questioned whether using family experiences to shape my thinking might detract from the quality and rigor of my scholarship. After all, there are few influences within the "academy" that encourage one to use practical experiences to shape theoretical formulations; although there are a few now, even these are under attack. I resolved this dilemma by reminding myself that it worked well for Piaget to observe his own children in conceptualizing his theory of child development; thus, using day-to-day experiences of my own family could be a powerful tool to enhance the depth and breadth of my own thinking. I will highlight three phases in my evolution of morphed perspectives: (a) moving from parent involvement to generic family support, (b) moving from generic family support to individualized family support, and (c) moving from the process of providing family support to the outcomes of family quality of life.

\section{From Parent Involvement to Generic Family Support}

The first conceptual highpoint from my morphed perspectives was the realization in the late 1980s that the focus on child developmental progress was trumping a sufficient focus on the process of supporting families. Jean Ann Summers and I wrote the following passage in 1987 to encapsulate our vision of the paradigm shift needed in the conceptualization of family support:

The term "parent involvement" sums up the current perspective. It means we want parents involved with us. It means the service delivery system we helped create is at the center of the universe, and families are revolving around it. It brings to mind an analogy about the old Ptolemaic view of the universe with the Earth at the center....

Copernicus came along and made a startling reversal-he put the sun in the center of the universe rather than the Earth. His 
declaration caused profound shock. The Earth was not the epitome of creation; it was a planet like all other planets. The successful challenge to the entire system of ancient authority required a complete change in philosophical conception of the universe. This is rightly termed the "Copernican revolution."

Let's pause to consider what would happen if we would have a Copernican revolution in the field of disability. Visualize the concept: The family is the center of the universe and the service delivery system is one of the many planets revolving around it. Now visualize the service delivery system at the center and the family in orbit around it. Do you see the difference? Do you recognize the revolutionary change in perspective? We would move from an emphasis on parent involvement (i.e., parents participating in the program) to family support (i.e., programs providing a range of support services to families). This is not a semantic exercise-such a revolution leads us to a new set of assumptions and a new vista of options for service. (pp. 295296)

To paraphrase the words of President John F. Kennedy, the plea was basically "to ask not what families can do for you as a service provider, but ask what you can do for families."

\section{From Generic Family Support to Individualized Family Support}

The Copernican revolution in the field of disability led me to the second conceptual highpoint of my career: the development of a family systems framework to guide professionals in gaining an individualized perspective of each families' strengths and needs for family support (Turnbull \& Turnbull, 2001a). Jean Ann Summers, Mary Jane Brotherson, and I synthesized systems theory and its applications from the theoretical and empirical literature in the fields of family sociology and family therapy in order to portray the individual and interacting components of family life. Using foundational concepts from the literature, we conducted qualitative research with a wide array of families to enable us to conceptualize a family systems framework. As illustrated in Figure 1, the family systems framework includes family characteristics, interaction, functions, and life cycle.

1. Family characteristics describe the characteristics of the whole family (e.g., size and form, cultural background, socioeconomic status, geographic location); the characteristics of individual members (e.g., nature of disability, health status, coping styles); and the family's special challenges (e.g., challenges over and above the disability, including poverty, child abuse and neglect, and substance abuse). With systems theory as a

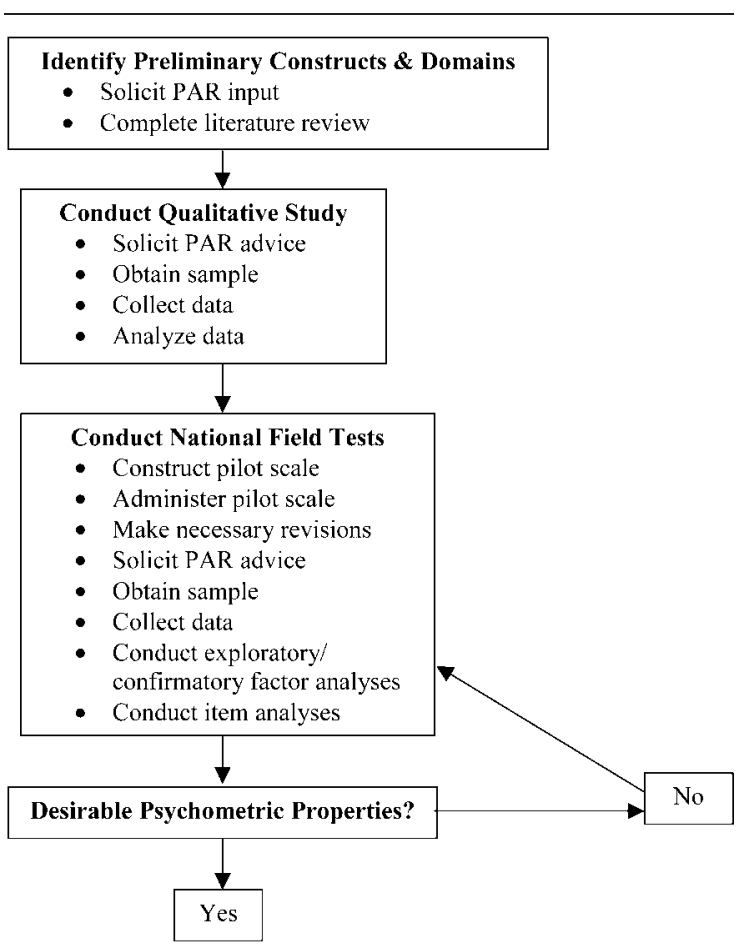

Figure 1 Phases of family quality of life research program. PAR = participatory action research.

guide, these characteristics are the input that shapes the way families interact.

2. Family interaction refers to the process of interaction among individual family members and subsystems, including marital, parental, sibling, and extended family. Interactions are influenced by the level of the family's cohesion and adaptability. Subsystems are influenced by the input of family characteristics, and, in turn, they lead to the output of family functions.

3. Family functions are the output of the interactional subsystems. The family fulfills its functions related to affection, self-esteem, economics, daily care, socialization, recreation, and education in light of its characteristics (input) and its interaction (process).

4. Family life cycle represents the element of change into the family system. Some changes are developmental, occurring when the family is transitioning from one lifespan stage to the other; and other changes are nondevelopmental, such as the sudden onset of an illness or a fire that destroys one's home. Family life cycle considerations continually produce change in the way the family interacts (process). 
This family systems framework has influenced my thinking, research, and writing significantly over the last 20 years. Family experiences were a strong factor in shaping the early development of the framework. I continue to filter my own family experiences and the experiences other families share with me through this framework in seeking insight that shapes my professional endeavors and family priorities.

Rud and I are currently completing the 5 th edition of our family textbook, Families, Professionals, and Exceptionality: Building Trust Through Partnerships (Turnbull, Turnbull, Soodak, \& Erwin, in press), in which we use the family systems framework as the basis of instructing future teachers on how to develop partnerships with families in order to build on individual strengths and addressing unique needs of their students.

\section{From Individualized Family Support to Family Quality of Life Outcomes}

Approximately 5 years ago, working with a large group of colleagues (Corine Frankland, Lesa Hoffman, Hasheem Mannan, Janet Marquis, Loui Lord Nelson, Jiyeon Park, Denise Poston, Matt Stowe, Jean Ann Summers, Rud Turnbull, and Mian Wang), my focus evolved from primarily reconceptualizing the process of providing individualized support to families to conceptualizing the outcomes of family support. It was at this time that my colleagues and I initiated the research program we have implemented for the last 5 years and that we anticipate continuing to implement at least for the next 10 to 15 years. Our focus has been on conceptualizing and measuring family quality of life as an outcome of policies and family support services. Nowhere in my own research has my noveau chapeau been more apparent than in this family quality of life research. I will briefly describe each phase of this research program (see Figure 2).

\section{Identify Preliminary Constructs and Domains}

The first step started with implementing a participatory action research approach, which refers to a process of conducting research collaboratively among researchers and intended beneficiaries (Santelli, Singer, DiVenere, Ginsberg, \& Powers, 1998; Turnbull, Friesen, \& Ramirez, 1998). The ultimate purpose of using this research approach is to assure that knowledge derived from research benefits families, administrators, service providers, and policymakers. Participatory action research reflects a fun-

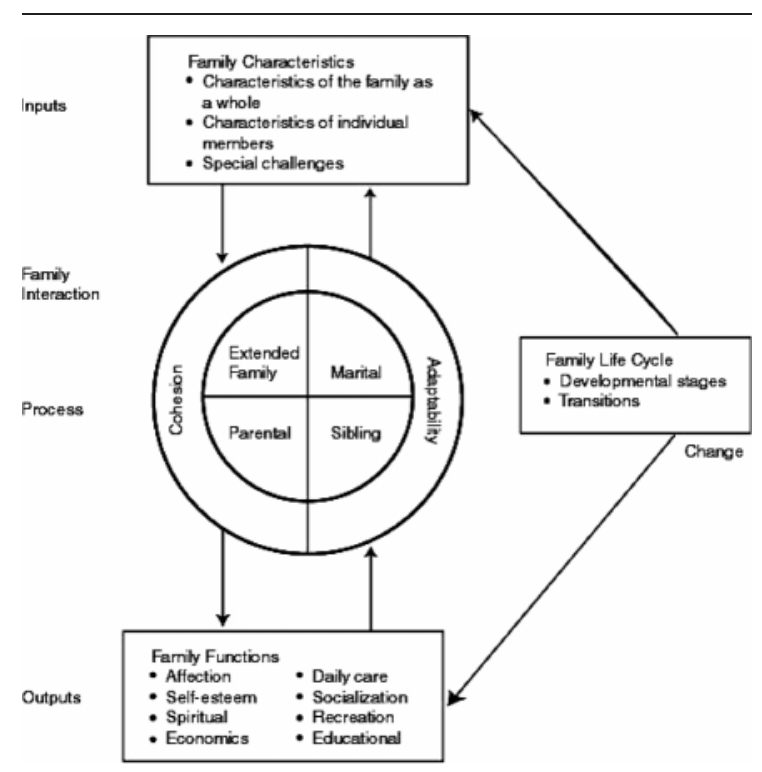

Figure 2 Family systems framework.

damental change: Families and other beneficiaries are valued partners with researchers in planning, conducting, disseminating, and utilizing research.

I am keenly aware that my family role has strongly influenced my commitment to a participatory action research approach. Generally, parents are interested in research that enhances policy and practice or yields solutions to challenges they face (Patterson, Behr, \& Blue-Banning, 1993; Turnbull, Blue-Banning, Behr, \& Kerns, 1987). Families have expressed concern about the time and effort that has gone into documenting what Antonovosky $(1987,1993)$ referred to as a pathogenic perspective, research that only explains stress, caregiver burden, depression, and other related outcomes. Alternatively, Antonovosky called for research with a salutogenic perspective, in which the focus is on the supports, resources, and interpretations that enable families to be resilient, experience well-being, and ultimately have a high quality of life. In the many experiences that I have had with participatory action research over the years, I consistently find that families value new knowledge to enhance their quality of life. They are looking for solutions to their needs as contrasted to a description of their pathologies.

In order to implement participatory action research, we sought the advice of families, service providers, researchers, and policy leaders from the out- 
set in envisioning how research could be carried out to enhance its ultimate benefit and ensure optimal rigor. In addition to using the participatory action research process, we also systematically reviewed literature on individual quality of life and emerging literature on family quality of life so that our work would be grounded in the most current knowledge.

\section{Conducting Qualitative Studies}

We implemented 33 focus groups and 34 individual interviews consisting of 187 individuals. The focus group and interview participants included family members (e.g., parents, siblings) of children and youth with a disability, individuals with a disability, family members of children and youth without a disability, service providers, and administrators (Poston et al., 2003). We asked general questions, such as:

1. When you hear the words family quality of life, what first comes to your mind?

2. Tell us about times when things have gone really well in your family. What helps things go well?

3. Tell us about times that have been especially tough in your family. What are the things that usually create tough times?

We used a number of probes to get more in-depth information from participants. We taperecorded all focus groups and interviews and engaged in extensive qualitative analyses. The transcripts from the focus groups and interviews resulted in 19,000 single-spaced pages of transcripts that were placed in Ethnograph (5.0), a software program for qualitative analysis. We used a constant comparative method of qualitative analysis (i.e., themes are constantly compared to each other to get a general framework that properly interprets data and the emerging interpretation is gradually reduced to produce a small set of higher level concepts).

We identified 10 domains of family quality of life that we divided into two categories: (a) Individually-Oriented domains-Advocacy, Emotional Well-Being, Health, Environmental Well-Being, Productivity, and Social Well-Being and (b) Family-Oriented domains-Daily Family Life, Family Interaction, Financial Well-Being, and Parenting.

Although conducting focus groups and interviews was extremely time-consuming, and ensuring a rigorous qualitative data analysis process took even more time, we are confident that the research program was launched with significant ecological validity. We particularly take pride in the diversity of family voices the sample represents. Because a number of our participatory action research partners were families from culturally and linguistically diverse backgrounds, they were especially effective in recruiting diverse families for participation in the research (Markey, 2000; Santelli, Markey, Johnson, Turnbull, \& Turnbull, 2001). This is an example of how participatory approaches can improve the rigor of research by ensuring that the sample is sufficiently diverse. Our research partners from diverse backgrounds even facilitated focus groups in their communities because they indicated that families would be far more likely to attend and would be more candid and forthcoming in their comments if "outsiders from the University of Kansas" were not present. A traditional problem with family research is that investigators have relied on convenience samples, which often results in research participants being primarily European Americans at the middleand upper-middle-class socioeconomic levels. Although it is necessary for these families to be proportionately represented in the research, it is inappropriate for them to be disproportionately represented. Alternatively, we had extensive diversity in our qualitative study.

\section{Conducting National Field Tests}

Based on the 10 domains identified through the qualitative research, our research team and partners wrote approximately 12 items for each domain from a 6th to an 8th grade reading level to cover the depth and breadth of themes raised in the focus groups. We conducted a national field test in two phases (Park et al., 2003; Turnbull et al., 2004; Wang et al., in press). Across the two phases, the samples included 1,700 family members drawn from early childhood and public school programs, family conferences, and family support programs in culturally and linguistically diverse areas. Our research partners, who were leaders in diverse communities, translated the surveys into Vietnamese, Korean, and Spanish so that the families they served could respond. To get a high number of family to respond, several program leaders suggested a family gathering in the evening with dinner, childcare, and transportation provided. We followed their advice, and they had staff present to read the surveys to families who could not read their native language or English. Furthermore, having family leaders "vouch" for us enabled families from culturally and linguistically diverse backgrounds to trust us enough to participate in the research. 
The final Beach Center Family Quality of Life Scale has 25 items divided into the following five subscales: Disability-Related Support, Physical/Material Well-Being, Emotional Well-Being, Parenting, and Family Interaction. The overall family quality of life model (tested at the subscale level) has excellent fit, $\chi^{2}(5, N=0)=3.41, p=.63$, comparative fit index $(\mathrm{CFI})=1.00$, root mean square error of approximation (RMSEA) $=.00$. Cronbach's alpha for the scale is .94. Each of the 5 subscales was shown to be unidimensional and internally consistent: Family Interaction, Parenting, Emotional Well-Being, Physical/Material Well-Being, and Disability-Related Support, $\alpha$ s $=.92, .88$, $.80, .88$, and .92 , respectively (Turnbull et al., 2004).

\section{Overview of Five Domains of Family Quality of Life}

One of the interesting findings from the qualitative research was families' perspectives on how they define their family membership. Rather than adhering to the United States census definition that a family is composed of a group of two or more people related by birth, marriage, or adoption and who reside together (Iceland, 2000), the families in our research included as family members people who are not necessarily related by birth, marriage, or adoption and who do not necessarily reside together. Based on families' descriptions, we concluded that an appropriate definition of family is as follows: "A family includes the people who think of themselves as part of the family, whether related by blood or marriage or not, and who support and care for each other on a regular basis" (Poston et al., 2003, p. 319). We define family quality of life as "conditions where the family's needs are met, and family members enjoy their life together as a family and have a chance to do things which are important to them" (Park et al., 2003, p. 368).

In this presentation I (a) provide a brief explanation of each of the five domains of family quality of life (professional hat), (b) illustrate the explanation with examples from my own family experiences (family hat), and (c) share morphed insights and next steps for addressing priority issues.

\section{Disability-Related Support}

This first domain of family quality of life focuses on support from other family members or from outside the family and provided in order to benefit the family member with a disability (Turnbull et al., 2004). Sample items include: My family member with special needs (a) has supports to achieve goals at school or work place, (b) has supports to achieve goals at home, and (c) has supports to make friends.

Family experience. Over our families' life cycle, there have been many highs and lows in the disability-related support that JT has received. The "lowest low" was when he was in the process of transitioning from high school to adulthood. This was in the late 1980s, and the high school program transitioned students with significant intellectual disabilities to the only adult services program in the community. This program provided the only option for living in a group home and working in a sheltered workshop. (Recreation was largely a bowling outing with the group home residents on Saturday evening.) This clearly was not the life that JT envisioned for himself nor one we envisioned for him. As we began learning more and more about supported employment that had started in the early 1980s in a number of places around the country, we kept asking that JT be given the opportunity for a "real job" and "real wages." Our request was interpreted as our being entirely "unrealistic" and "in denial" about the extent of JT's disability.

It is a very long story, which is impossible to relay in full at this point. The "clincher" to JT's experience in the adult agency was that he picked out one resident to hit and choke every time he saw him in the group home and sheltered workshop; that resident was the son of a state senator. This may have been one of the most self-determined acts in which JT ever engaged because it resulted in very swift expulsion from the adult program. It was grueling for Rud and me because we received multiple phone calls every day reporting to us in great detail his most recent aggressive incident. I recall telling Rud that I felt as if a "guillotine was pulled above our heads," and we were just waiting for it to drop.

At the age of 19, JT was expelled from the only adult program in the community, and he had a very "profound reputation." JT was clearly in a black hole. Although he had a home when he came back to live with us, his school eligibility was over; and he had no job, no transportation, no friends, and no community inclusion. One can only imagine how difficult it was for us to provide time and attention to Amy and Kate given that we were each investing around 20 hours a week in advocacy for $\mathrm{JT}$, in addition to trying to do our jobs and generally keeping life together for the family. It was not just 
JT in a black hole; indeed, our whole family was in a black hole.

I will now zoom forward about 12 years to the year 2000. Suffice it to say in the intervening years, we learned a great deal about supported housing long before it was a national priority. Starting in 2000, JT qualified for individualized funding, which means that he himself receives directly the financial support from the Medicaid Waiver that traditionally has gone to adult agencies. Rather than the money being directed to the adult agency, which would then have a "slot" for JT in their employment and/or a "bed" for him in its residential program, the money comes directly to a fiscal intermediary who disburses the money to JT and to the people who provide support to him. The amount of funding for individuals with disabilities depends upon their support needs. Because JT requires 24/7 support and has intensive needs across all settings, the amount of his Medicaid support is quite substantial. The sample items related to Disability-Related Support are those that support the achievement of priority goals across multiple settingsschool, work, home, and in the community with friends. Individualized funding is unequivocally the primary basis of JT's support. JT and all of us clearly emerged from the black hole into a rainbow of possibilities.

In addition to the individualized Medicaid funding, JT qualifies for housing assistance and for Social Security Disability Income (SSDI), which he receives because he has worked for 40 consecutive quarters (10 years) but still has a substantial disability and also because he is the son of a man who is receiving Social Security retirement benefits. JT also works 20 hours a week at the University of Kansas and, thus, has his salary and the University's benefits package. By pooling these resources, JT can clearly afford to live his life to the fullest.

JT does not count money or have the capacity in any way to manage his own fiscal affairs. Through the collaboration of the fiscal intermediary, JT's housemate, and Rud, JT receives the benefits of this funding without needing to have the competence to manage the funds himself.

Anytime JT hears us use the words "JT's house," he quickly and emphatically corrects us and says, JT's "home." Jay is very insistent that he has a home and not a house. Homes consist of not only physical settings, but also of relationships, comfort zones, and privacy. JT's two-story home has two living areas. The first-floor living area includes JT's bedroom, along with an additional bedroom, a living room, a dining room, a kitchen, and a family room. The second living area is on the second floor and is where JT's housemate has his bedroom, family room, and office. This means that JT and his housemate can have their own privacy but can also share spaces on each floor.

JT's current housemate of almost 2 years is Bryan Riffel. Bryan is 38-years-old and believes at this point that he wants to make a lifetime commitment to being JT's housemate and companion. He receives pay from the individualized funding that enables him to devote primetime attention to supporting JT, which includes going through the wakeup/dressing routine in the morning, preparing meals, overseeing JT's very busy weekly schedule of paid and volunteer work, and coordinating the "comings and goings" of the many friends and personal assistants who are part of JT's life.

Bryan does not perceive of himself as JT's "staff," and neither do JT nor we. He is a housemate and careprovider, and he and JT have developed a companionable bond. We have very much sought to have the kind of relationship or connection that is not hierarchical or controlling. Unlike group homes, Bryan does not provide support on a shift basis. It is his home, too, and he enjoys the daily/ weekly rhythms of living there along with JT.

When Bryan expressed the expectation that he would like to make a lifetime commitment to JT, it was music to our ears! I think one of the greatest challenges that families face is the distance of the long-term marathon of family responsibility that they have versus the relatively short segments of time during which different service providers are involved with them. In our experience, families yearn for long-term commitments! Neither Bryan, JT, nor we know exactly how this will work out, but we eagerly embrace Bryan's intentions. Like most parents, our greatest hope is that JT has caring and competent support from people who truly care about him. We especially hope for this type of support system when we die or are no longer able to oversee his support and make sure that it meets his priority standards of quality. Although it is clearly our hope that JT, Amy, and Kate will always have a loving relationship, we worry about responsibilities that Amy and Kate may need to assume when we are no longer able to do so. We very much believe that they are entitled to live their lives in the least restrictive environment, which means that they will not be obliged in any way to orient their 
lives around the provision of support to JT after we die. Just as self-determination is an important element of JT's life, so is it for his sisters, as well.

\section{Morphed Professional Insights and Next Steps}

In the United States the individualized funding initiative is picking up substantial momentum. The most helpful current resource that we have found is a manual reporting the results of a study carried out by the National Association of State Directors of Developmental Disabilities Services to describe the approaches various states are using to transition from an agency-directed budgeting process to an individual budgeting process (Moseley, Gettings, \& Cooper, 2003).

I want to address two insights concerning individualized funding that have influenced my professional orientation. The first insight is that Rud and I have learned how important it is to recognize the impact of one's significant intellectual disability on being able to manage the myriad responsibilities associated with individualized funding (Turnbull \& Turnbull, 2001b). Frequently, self-advocacy leaders in the individualized funding movement advance the position that families should "mind their own business" and ensure that adults with intellectual disabilities have full autonomy in accessing and managing individualized funding. I respect the sincerity of advocates who advance this view. The major problem Rud and I have with this position is that we wonder who in the individualized funding advocacy community speaks for the people with significant intellectual disabilities who do not have the foundational skills to manage the complexities of financial, legal, and other types of decisions. Just a few of the experiences that had to be successfully negotiated for JT to reap the benefits of individualized funding included engaging in several administrative hearings when the state first denied eligibility to JT, filling out the extensive paperwork to obtain SSDI and Section 8 eligibility, researching and securing the most advantageous mortgage rates, looking at many houses before making a final determination of which house to buy and securing the appropriate mortgage, and developing and implementing a budget consistent with the requirements of each of the diverse funding sources.

Currently, there is such a steady stream of paperwork that Rud estimates he spends 10 to 15 hours a month attending to the fiduciary and administrative responsibilities. We wonder what op- portunities JT would have had for the high quality of life he experiences if, as a family, we "minded our own business" and turned the paperwork over to JT to either complete or to find someone who could assist him who is not a family member. We wonder how it would impact Bryan's job satisfaction if he were required to do this paperwork and, further, how long it would take him to do it. One of the reasons that Rud does not need to spend significantly more than 10 to 15 hours a month on the paperwork is that he is highly familiar with it and has been doing it for years. His background as a lawyer prepares him to deal with the "legalese" of the majority of the documents JT receives frequently that require completion.

Right now, as a field, we desperately need to develop an infrastructure to support both individuals with disabilities and their families as they handle the administrative load in order to receive the benefits of individualized funding. A few communities have innovative broker agencies, but for the most part the options are to receive full services from agencies or to manage on your own your full affairs through individualized funding. We hope that the self-advocacy community and other disability advocates who support the view that families should "mind their own business" will recognize the need for long-term support from people who have a personal stake in the individual's quality of life. Rud and I believe that sometimes supporting independence means providing the ongoing and intensive/pervasive supports that enable people with significant intellectual disabilities to enjoy the same lifestyle opportunities that people do when they do not experience significant intellectual disabilities. We believe it would be beneficial if individuals in the self-advocacy movement would explore the extent to which people with significant intellectual disabilities are fully represented in the decisionmaking process on key positions.

My second insight relates to the role of siblings in providing long-term support. If Jay could be fortunate enough to have Bryan in his life over the long-term, Amy and Kate could have a more typical sibling relationship with JT, sharing reciprocal love and support without having the primary responsibility for overseeing his care. It is critically important that we learn far more about successful ways to support siblings to provide long-term support when parents are no longer able to do that. We know from research that sisters are more likely to anticipate co-residence as contrasted to brothers 
and that siblings are more likely to plan co-residence with sisters who have less severe retardation (Krauss, Seltzer, Gordon, \& Friedman, 1996). Future research is needed on a variety of approaches that families have used with success to "pass the baton" of long-term support to others-nonrelatives such as Bryan and to siblings who "stay the course" over decades. Although I included nonrelatives in the definition of family that I provided earlier, Bryan clearly qualifies as a family member. (Although JT and Bryan are not formally related, they do support and care for each other on a regular basis, and they do think of themselves as part of each other's family. I believe that evolving new ways to support individuals with significant intellectual disabilities through individualized funding to enjoy full community inclusion will mean reconfiguring traditional family relationships into new possibilities.)

Although supports in the field of developmental disabilities are often categorized according to whether the supports are directly for the individual with a disability or for the family, our family experience suggests otherwise. When funding goes to JT to enable him to have the supports that he needs on a $24 / 7$ basis, it might be correctly called individual supports to him. However, individual supports clearly improve the quality of life for all family members. We could paraphrase the saying that "When mama is happy, everyone is happy" to our family situation, affirming that "When JT is happy, everyone is happy."

I am very pleased to have the opportunity to appoint an AAMR committee to focus on policy, research, and training related to the effective implementation of individualized funding. Chas Moseley and Rud Turnbull are co-chairing that committee. The AAMR will provide significant national leadership related to individualized funding over the next several years.

\section{Physical/Material Well-Being}

Physical/Material Well-Being refers to the resources available to the family to meet its members' needs (Turnbull et al., 2004); for example (a) My family feels safe at home, work, school, and in our neighborhood; (b) my family gets medical care when needed; and (c) My family members have transportation to get to the places they need to be.

Family experience. I want to address the indicator of feeling safe at home and within all environments. As we look back over our family life cy- cle, our biggest threat to safety stemmed from extremely aggressive behavior on JT's part during his adolescence. This behavior involved hitting and hair-pulling at home, school, work, and community settings. This aggressive behavior actually occurred rather infrequently; however, when it did occur, it was exceedingly intense. It was especially threatening in our family given that JT is 8 years older than Amy and 11 years older than Kate. Thus, his physical size and strength meant that his young sisters were at a distinct disadvantage when he displayed aggressive behavior in their presence. There were times when Amy, Kate, and I did not feel physically safe being around him, nor were we and Rud emotionally secure "walking a tightrope" between JT's rapid-cycling moods and his ability/inability to maintain control. Looking back on these years, we wish much more had been known about positive behavior support, crisis intervention, and emotional coping with unexpected trauma. I especially want to address emotional coping with unexpected trauma.

It was not until Amy and Kate were adults that they were able to reflect back on these early experiences and describe to us, for the first time, the fear they experienced associated with these episodes. Though at the time Rud and I did not realize it, they revealed that their fear was not at all limited by the rather infrequent occasions on which the aggressive episodes happened. They so frequently worried that there might be outbursts when, in fact, there were no outbursts at all. Thus, one of the basic tenets of the behavioral approach is that behavior must be observed, but for Amy and Kate fear occurred frequently in the absence of observed behavior. When we asked them why they did not share these fears with us, they indicated that they did not "want us to worry that they were worried" and that they even felt "guilt" and "shame" having feelings of fear about their brother. They also felt that part of their "loyalty" as a family member was to keep this "family secret" in order to protect JT's reputation, individually, and the reputations that Rud and I have in the field, on a professional level. In other words, they felt "silenced," partially because we wore two hats. Another very complicated family factor was that we were truly confused about the extent to which JT should be held accountable for his behavior and experience consequences for it versus the extent to which his behavior was related to factors beyond his control, such as biological and/or hormonal imbalance, irresistible impulses, 
and lack of sufficient communication skills. Thus, after aggressive incidents occurred, we were torn between empathetically comforting JT because he was so devastated about what he had done versus disciplining him with consequences. One of the very frustrating aftermaths would be for JT to be highly repetitive (beyond some people's imagination to even envision how repetitive he actually was) in expressing his remorse, disappointment in himself, and promises to never do it again. It is hard enough for adults to experience and express emotions associated with these highly unfortunate situations; just consider how confusing it must have been for Amy and Kate, as well as JT.

\section{Morphed Insights and Next Steps}

In reflecting on our experiences as parents, we believe that not providing sufficient emotional safety for Amy and Kate represents our biggest mistake. We, like people in the field of behavioral psychology, were oriented to reducing the frequency of aggressive behavior instead of recognizing that JT's aggression could be a form of domestic violence with mental health repercussions for all family members-especially for children. With all the innovative research being done in positive behavior support, we have not seen research to date that addresses not just physical safety but also emotional safety of siblings and other family members. We need to bring fear of aggressive behavior out of the family closet and provide families with knowledge, skill, and adaptive strategies to process and resolve emotional aspects of a family member's aggressive behavior. I believe this is especially important for brothers and sisters who are young and, understandably, have not had an opportunity to develop the same coping strategies that adults are likely to use in similar situations.

The research of Hastings and his colleagues on the use of adaptive and maladaptive coping strategies of staff working in community agencies with people who have problem behavior is especially pertinent (Hastings, 2002; Hastings \& Brown, 2002; Mitchell \& Hastings, 2001). Just as Hastings and colleagues have investigated the impact of problem behavior on the psychological well-being of staff, I encourage researchers interested in family support and/or positive behavior support to start inquiring into effective coping strategies for siblings and parents to deal with aggressive behavior in home environments and family routines. Researchers need to address in detail how siblings and parents should verbally and nonverbally process these incidents so that they achieve emotional clarity. We critically need a salutogenic focus as contrasted to a pathogenic one (Antonovosky, 1987, 1993) in focusing on effective coping strategies for parents, siblings, and the individual with the disability to ensure that everyone feels safe at home. In maximizing an interdisciplinary perspective, I expect there is much to be learned in the field of developmental disabilities from the field of domestic violence on emotional resilience, family communication, and prevention.

\section{Emotional Well-Being}

The third domain of family quality of life is Emotional Well-Being, which refers to the feeling or affective part of family members and family life (Turnbull et al., 2004). Sample items include (a) My family members have friends or others who provide support. (b) My family has the support we need to relieve stress. (c) My family members have some time to pursue their own interests.

Family experience. I believe that two of the most important contributions that can be made to families are to facilitate friendships for the member with a disability and to support siblings in how to talk with their friends about their brother or sister who has a disability. It is painful to remember that JT really did not have any peer friends when he was growing up. He had our family's friends, people who were paid to be with him, the staff of special populations programs, and students who received practicum credit for spending time with him, but he had no peer friends.

One of our most painful memories was the first time that JT ever received a phone call when someone asked for him, and we did not know who the person was. JT was in his early teens and had already gone to bed when the phone call occurred. We quickly rousted him from sleep and rushed him to the phone. After a very brief conversation while JT had a very perplexed expression on his face, he hung up the phone. When we asked him who had called, he responded "I don't know." We then asked, "What did they say?" And JT responded, "They said wrong number." It is a sad commentary on the state-of-art implementation of inclusion when you are in your early teens before you have your first phone call and then the call turns out to be "the wrong number." JT's experience is indicative of the social isolation from genuine friendships 
that occurs for many people with intellectual disabilities.

When JT was in elementary and secondary school, the curriculum emphasis was primarily on functional academic skills. Support that would have made a critical difference in his quality of life and that of our family early on would have been to facilitate connections between him and other children in the neighborhood and school, his cousins, peers in his church school program, and peers at the community arts center where he might have been able to take some classes in music, which is his passion. Potential friends needed competence and comfortableness in interacting with JT, idiosyncrasies and all.

Amy and Kate also needed support in knowing how to answer their friends' questions-"What's wrong with your brother?" Interestingly, the first time that either of them was asked this question was at their respective fifth birthday parties. By the age of 5 , their peers were curious about why JT was different, but he was not as different to Amy and Kate as he was to their peers. Amy and Kate had grown up with him, and he was so familiar to them. Thus, when they were first asked the "What's wrong?" question, they did not understand its implications. Families need support in handling issues with siblings' friends at each lifespan stage.

When the girls were 5 , their need for competence in answering questions about their brother was very different from their need when they were teenagers, and they were ashamed of not only JT but every family member-especially their parents! We have continued to laugh over the years about a family presentation that we made at the University of North Carolina at Chapel Hill in the mid 1980s. At that time, Kate was in 6th grade. When sharing her perspective, she commented that many people believed she was embarrassed about having a brother with mental retardation, but what these people did not realize was that her "parents embarrass her far more than her brother!" She then turned and pointed to her father and said to the audience, "How do you think it makes me feel when my dad wears a bow tie like the one he has on today?" The bottom line is that it really is important to consider developmental needs of children and how explanations need to be calibrated accordingly.

\section{Morphed Insights and Next Steps}

The most successful friendship facilitation program we have encountered is Natural Ties. It began at the University of Kansas, evolving from a friendship that JT developed with Pat Hughes, a member of a KU fraternity. We have wonderful memories of when JT first started hanging out at the fraternity house. This was just after he had been expelled from the community agency in Lawrence, and when he was in the depths of the black hole. The timing was highly fortuitous because this was around the time that the movie, Rainman, was very popular. To be totally honest, I think perhaps a number of the guys in the fraternity really did want to be Tom Cruise! On a serious side, from the outset, JT had such fun at the fraternity with the guys listening to music, going to ballgames, sharing meals, and going to parties. Rud and I learned a very profound truth from these experiences: In fraternities, guys do the behaviors every Saturday night that causes people with developmental disabilities to get kicked out of programs. JT raised the level of appropriate behavior at the fraternity! As JT's participation in the fraternity continued, two of his fraternity brothers, Pat Hughes and Corey Royer, approached us suggesting that JT should get to move out of his parents' home and that they would like to be his roommates.

From its beginning at $\mathrm{KU}$ as a student organization, Natural Ties then spread to other universities. It is a student-directed organization in which university students and adults with disabilities get together on a weekly basis to share friendship and have fun together. The unique aspect of Natural Ties is that the adults with disabilities are matched with a campus organization first and then with several students within that campus organization. Thus, there is a closer connection with several specific members of the student organization but also a broad general connection with all members. For example, JT is matched with the Kappa Sigma fraternity. He gets together with several of the guys from the fraternity every Wednesday evening for a shared activity and then a larger Natural Ties group meeting. Throughout the week, there are also occasions when he and his buddies just hang out or do some kind of activity together. The value of JT and other individuals with intellectual disabilities being linked with a campus organization is that the campus organization replenishes itself every year with new members. Thus, as the closer friends that JT has in the fraternity graduate, there are new ones to maintain the connection and to evolve into new friendships. JT has been part of Natural Ties for over 15 years. Many friends have come and gone, 
and the ones who have left frequently keep in touch and come to see JT when they are back in Lawrence.

Natural Ties chapters could be started at every college and university. In fact, it is a concept that works with any organization where most of the people do not have disabilities. Thus, scouts, 4-H, religious groups, Jaycees, Kiwanis, as well as other organizations could use this same model to facilitate community inclusion.

One of the models for supporting sibling friendships that has been around the longest is Sibshops, run by Don Meyer. Sibshops, which is affiliated with The Arc of the U.S., offers many alternatives for providing support to siblings, ranging from chat rooms to group meetings to newsletters. A current challenge is that Sibshops needs (and deserves) a stable funding base.

A substantial amount of research on siblings has been published in AAMR journals as well as in other journals. Unfortunately, this research has not yet been synthesized and brought together to elaborate on support strategies that would be especially helpful to siblings. A promising partnership could be established between the Sibshops organization and an AAMR Sibling Research Synthesis Committee to pull together the knowledge base and apply it. Hundreds, even thousands, of siblings across the country could benefit from empirically based knowledge regarding friendship facilitation as well as knowledge on a range of other topics.

\section{Parenting}

The fourth domain of family quality of life is Parenting, which refers to the activities that adult family members do to help children grow and develop (Turnbull et al., 2004). Sample items include the following: (a) Family members help the children learn to be independent. (b) Adults in my family teach the children to make good decisions. (c) Adults in my family have time to take care of the individual needs of every child.

Family experience. I especially want to address the first indicator of families having time to take care of the individual needs of every child. Looking back on our family life, it was challenging in the span of 24 hours a day/7 days a week to find sufficient time to address all of JT's needs.

As I have previously stated, it was particularly challenging to keep our family life moving ahead when he was transitioning from high school to adult services. Both the high school system and the

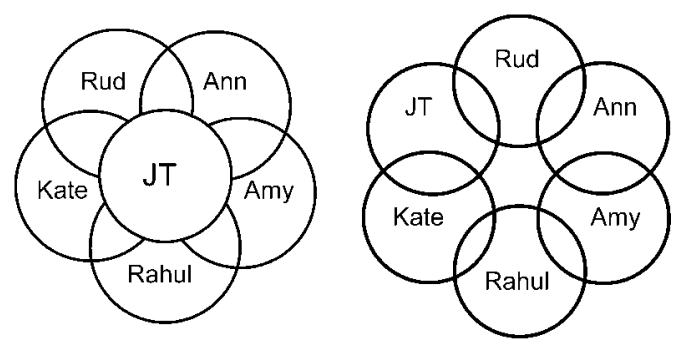

Figure 3 Dynamics of family life when there is a member with a disability.

adult service system needed significant quality enhancements. Often, there is the expectation that parents will pick up the slack when programs are not of sufficient quality and engage in advocacy to either improve the existing program or start a new one. We found our 20-hour-per-week advocacy commitment to be a very heavy burden. Aside from this advocacy role, parents need to teach many skills that are related to behavior, communication, daily living, and a host of other needs.

Over the years, we perceived an explicit and implicit message from many disability professionals that we should keep JT in the center of family life and make sure that he gets follow-through education across settings, including home, neighborhood, and community activities. In Figure 3 (on the left), we illustrate the members of our nuclear family with JT in the center. Also in Figure 3 (on the right), we illustrate a different way to live family life, which is to recognize JT as one of six family members with no more claim to "center stage" than any other family member.

Given that it is impossible to do everything that needs to be done and that placing the member with a disability in the center of family life is not a good long-term alternative, priorities clearly have to be set. If I could start parenting again with the benefit of the knowledge that I acquired over the last 30 years, I would give far more attention to teaching self-determination skills starting in the earliest years. As parents, it was very easy over the years to fall into the trap of making decisions on behalf of JT and taking action to implement those decisions rather than taking the time to go through the structured process of helping him from early on to develop competence in the problem-solving process. Given that there is neither enough time nor energy to teach everything nor to advocate for ev- 
erything, I believe self-determination clearly is a priority. It is a pivotal skill producing multiple positive effects.

\section{Morphed Insights and Next Steps}

Research points to the long-term positive outcomes of self-determination. Self-determined individuals with intellectual disabilities are more likely to achieve more positive adult outcomes, such as earning more money per hour and experiencing a higher quality of life (Wehmeyer \& Schwartz, 1998). High school students who are self-determined are more likely to join their families and teachers in making important decisions about their curriculum and extracurricular activities (Sands, Spencer, Gliner, \& Swaim, 1999).

Some of the research at the Beach Center that excites me the most is the impressive work of Dr. Mike Wehmeyer and Dr. Susan Palmer in focusing on how to best prepare parents and teachers of children and youth to promote their children's self-determination (Palmer \& Wehmeyer, 2002; Wehmeyer, 2002; Wehmeyer \& Palmer, 2000). A key element of family quality of life is recognizing that individuals with disabilities, even at very young ages, can be significant partners in making decisions about what is important to them and determining what needs to happen to match the supports they need with the preferences they want to actualize. The best way to promote self-determination is through partnerships among service providers, children with disabilities, family members, and other key people who have influence in community settings where the child and family would like to participate.

New partnership models for promoting self-determination need to be developed, evaluated, and disseminated. You can find the research of Wehmeyer and Palmer on the Beach Center's website (www.beachcenter.org, click self-determination on the home page, and then click research on the next page) in three formats-one page overview, 2- to 3 -page research highlights, and full text articles. You can also download the full copy of their manual Self-Determined Learning Model for Early Elementary Students: A parent's guide (Palmer \& Wehmeyer, 2002).

\section{Family Interaction}

In the fifth and final domain, Family Interaction, the focus is on the relationships among family members (Turnbull et al., 2004). Sample items in- clude: (a) My family members talk openly with each other. (b) My family enjoys spending time together. (c) My family members show that they love and care for each other.

Family. Positive relationships between and among family members, I believe, are absolutely essential to family quality of life. In fact, a theme pervading all domains comes back to the first indicator in our list here: "My family members talk openly with each other."

1. Regarding Disability-Related Support, family members need to talk with each other about resources available, how they are accessed, and what the future vision is for continuing these resources.

2. Regarding Physical/Material Well-Being, family members need to talk about their feelings of safety and fear and what it will take to minimize or prevent fear and to enhance a sense of security.

3. Regarding Emotional Well-Being, families need to talk about their desires for friendships with others, how they address the disability-related questions and people who stare, and how they can help others feel competent and comfortable.

4. Regarding Parenting, family members need to talk with each other from the earliest ages about their preferences, options they might consider for problem-solving, and pros and cons of different alternatives.

5. It is in the domain of Family Interaction that we address the family's capacity to talk openly with each other. When families are able to talk openly with each other, they are far more likely to experience other indicators such as the other two listed here-enjoying spending time together and showing that they love and care for each other.

As I reflect on our family experience, I recall times when we were brought up short in our capacity to talk with each other, even though we perceived that we had very open family communication. One of my most poignant memories was about 20 years ago when JT was 16-years-old and Amy was 8. The Charles Kuralt show Sunday Morning came to Lawrence and spent several days with us to develop a feature story about family life when a member has a disability. Because Amy and Kate were young, we decided in advance that they would not be interviewed individually but that pictures of them could be taken in their interactions with JT. Before we were able to stop the interview one even- 
ing, the CBS commentator had a microphone around Amy's neck and was asking her what it was like to have a brother with a disability. She responded that she really did not think about him having a disability because after all, as she said, "JT likes to sing, and I like to sing. He likes to dance, and I like to dance. I think we're a lot more alike than different." Wanting to explore this issue with more candor, the CBS commentator kept probing about whether or not there were things that Amy worried about because JT had a disability that she did not worry about concerning herself given that she did not have a disability. After several probes and pushes, we almost fainted when Amy, with a worried look on her face, admitted that "I really worry about where JT will live when he is an adult and where he will work. If he doesn't have a home, he can live in my home. I don't want him to live on the street and be a bum when he grows up." The poignancy of Amy's fear about JT's "being a bum" put the CBS commentator at a loss for words, and there was a long, awkward, painful silence.

As parents, we were shocked that Amy was experiencing these concerns, because "the Pollyanna viewpoint" pervaded her typical attitude about JT's future. It was rather late in the evening when the interview occurred, and Rud and I felt that we should not launch into exploring Amy's feelings at that moment. The next morning we did not want her to leave for school before we probed her thinking and gave her information about what we anticipated in the future. She was in the bathroom brushing her teeth, the school bus was honking in front of our house, and Rud was seated on the bathtub giving her the equivalent of a law school course on last wills and testaments, trusts, estates, antidiscrimination, and community inclusion. (Thankfully, Rud had learned his lesson and was not wearing a bow tie!) We did not want her to experience one more day of her 8-year-old life worried that JT would be a "bum." When we asked where her concern had come from, Amy explained that she had seen a program on television where a person with a developmental disability lived on the streets, and it made her worry that might happen to Jay as well. Had it not been for the CBS commentator, it may have been a long, long time before we openly, as a family, talked about how to move from her fears about JT's future to excitement that JT could have a disability and still "get a life" that he wanted to live.

As the years have gone by, Amy and Kate now live far from Lawrence, but it is still critically im- portant to explore ways that we can talk openly as a family about ordinary and extraordinary topics. This becomes more challenging given that JT does not read, write, or talk in extended conversations. New vistas of possibilities for family communication are possible through assistive technology. JT has been most fortunate to benefit from the work of Dr. Dan Davies and his colleagues at AbleLink, an innovative technology company in Colorado Springs. I encourage you to visit their website (www. ablelinktech.com) to learn more about their products that can enhance the quality of communication between individuals with significant intellectual disabilities, their families, and everyone else in their lives. A product that has substantially advanced JT's family communication is Web Trek Connect, which is designed for people who have significant challenges with reading, writing, and the requirements of using a typical e-mail program. Web Trek Connect enables JT to send an audio e-mail by clicking on the receiver's picture and speaking his message into the computer microphone. In fact, JT's favorite e-mail messages are the ones he sings to people. When he receives a message back, the email is read aloud to him.

An example is a message that JT recently sent to Amy, who, as I mentioned earlier, is expecting a baby in January. After we told him about Amy's pregnancy, he was absolutely delighted and kept referring to himself as "Uncle JT." When we suggested that he might e-mail Amy to share his excitement, he chose to sing to her "Rock-a-Bye Baby." So his e-mail consisted of singing this song with great gusto, serving as his own symphony conductor by waving his arms to "conduct" his performance. Then he signed off by saying that it was from "Uncle JT." Amy's return e-mail was as follows:

Hey T-Man,

What's shakin'? It was wonderful to hear your energetic voice on my email. I love hearing you sing about our baby. It really did bring tears to my eyes, JT. Can you believe you're going to be Uncle JT? Thanks for taking the time to brighten my day with your singing! I can picture you tapping your fingers and moving your head around.

You are the greatest brother! I miss you and look forward to your next email.

Love you, Amy

Morphed insights and next steps. As professionals, I believe that we need to start during the early intervention years and continue throughout the family life cycle with practical information for families 
on how to initiate and carry out conversations on very sensitive topics. It would be very helpful to synthesize what we know from research on positive family interaction and communication so that empirically based strategies could be shared with families in family-friendly ways. It would be helpful to learn more from self-advocates about their preferences for how family communication on sensitive topics might be carried out. A new book that I found especially informative is Reflections From a Different Journey: What Adults With Disabilities Wished All Parents Knew (Klein \& Kemp, 2004). It is extremely insightful to learn from the perspectives of adults with disabilities what they like and do not like about their family relationships. It is not surprising that many of their comments focus on communication issues. One of the limitations of this book for the developmental disabilities field, however, is that the vast majority of contributors have physical, sensory, or mental health disabilities. We need to hear more from the self-advocacy community within the intellectual disability field about suggestions for positive family communication. In addition, it would be helpful to know more from parents, siblings, and extended family members about what has and has not worked for them as a way to compile successful strategies. Furthermore, most families do not know what is possible through assistive technology, and this whole area of communication enhancement needs far more attention.

Perhaps an AAMR member might be interested in preparing a research synthesis of the current knowledge base with suggestions for future research priorities that would be especially helpful in rounding out our understanding of positive family communication. This synthesis needs to be disseminated to professionals as well as families. Research on family preferences for receiving information indicates that most families prefer formats that are short, incorporate quotes and firsthand perspectives from people in similar situations, and are free (Ruef \& Turnbull, 2002). Families also recommend webbased stories, tips, and videos.

\section{Conclusion}

Rud and I have six degrees between us, but we frequently say that "JT is our best professor." Over the years, he has continued to teach us lessonssometimes more than we wanted to learn. We often comment that what makes him such a challenging professor is that "he so often gives us the final exam before we've had the course." This means that when we fail the final exam, he takes us back through "remedial learning" until we master the lessons required to calibrate his supports and services in order to ensure his individual quality of life and our family's quality of life.

I hope that my morphed perspectives-family and professional combined-will illuminate important next steps that professionals and family members might take to increase the likelihood that families throughout the United States and, indeed, throughout the world, who have a member with an intellectual disability will have genuine opportunities to experience and sustain family quality of life.

In closing this paper, I also close my term as president of AAMR. The best way I know to express my sentiments is to draw on the words of Dag Hammarskjöld (1905-1961): "For all that has been, thanks; for all that will be, yes!"

\section{References}

Antonovosky, A. (1987). Unraveling the mystery of health. San Francisco: Jossey-Bass.

Antonovosky, A. (1993). The implications of salutogenesis: An outsider's view. In A. P. Turnbull, J. M. Patterson, S. K. Behr, D. L. Murphy, J. G. Marquis, \& M. J. Blue-Banning (Eds.), Cognitive coping, families, $\mathcal{E}$ disability (pp. 111122). Baltimore: Brookes.

Hastings, R. P. (2002). Do challenging behaviors affect staff psychological well-being? Issues of causality and mechanism. American Journal on Mental Retardation, 107, 455-467.

Hastings, R. P., \& Brown, T. (2002). Coping strategies and the impact of challenging behaviors on special educators' burnout. Mental Retardation, 40, 148-156.

Klein, S. D., \& Kemp, J. D. (2004). What adults with disability wish all parents knew: Reflections from a different journey. New York: McGrawHill.

Krauss, M. W., Seltzer, M. M., Gordon, R., \& Friedman, D. H. (1996). Binding ties: The roles of adult siblings of persons with mental retardation. Mental Retardation, 34, 83-93.

Markey, U. A. (2000). PARtnerships. Journal of Positive Behavior Interventions, 2, 188-189, 192.

Mitchell, G., \& Hastings, R. P. (2001). Coping, burnout, and emotion in staff working in community services for people with challenging behaviors. American Journal on Mental Retardation, 106, 448-459. 
Moseley, C. E., Gettings, R. M., \& Cooper, R. (2003). Having it your way: Understanding state individual budgeting strategies. Alexandria, VA: National Association of State Directors of Developmental Disabilities Services.

Palmer, S. B., \& Wehmeyer, M. L. (2002). Self-determined learning model for early elementary students: A parent's guide. Lawrence: The University of Kansas, Beach Center on Disability.

Park, J., Hoffman, L., Marquis, J., Turnbull, A. P., Poston, D., Mannan, H., Wang, M., \& Nelson, L. (2003). Toward assessing family outcomes of service delivery: Validation of a family quality of life survey. Journal of Intellectual Disability Research, 47, 367-384.

Patterson, J. M., Behr, S. K., \& Blue-Banning, M. J. (1993). Putting participatory research into action: Conference dialogue between family members, providers, and researchers (pp. 289_ 299). In A. P. Turnbull, J. M. Patterson, S. K. Behr, D. L. Murphy, J. G. Marquis, \& M. J. Blue-Banning (Eds.), Cognitive coping, families, Eु disability (pp. 111-122). Baltimore: Brookes.

Poston, D., Turnbull, A., Park, J., Mannan, H., Marquis, J., \& Wang, M. (2003). Family quality of life outcomes: A qualitative inquiry launching a long-term research program. Mental Retardation, 41, 313-328.

Ruef, M. B., \& Turnbull, A. P. (2001). Stakeholder opinions on accessible informational products helpful in building positive, practical solutions to behavioral challenges of individuals with mental retardation and/or autism. Education and Training in Mental Retardation and Developmental Disabilities, 36, 441-456.

Sands, D. J., Spencer, K., Gliner, J., \& Swaim, R. (1999). Structural equation modeling of student involvement in transition-related actions: The path of least resistance. Focus on Autism and Other Developmental Disabilities, 14, 17-27.

Santelli, B., Markey, U. A., Johnson, A., Turnbull, R., \& Turnbull, A. (2001, March/April). The evolution of an unlikely partnership between researchers and culturally diverse families: Lessons learned. TASH Newsletter, 21-25.

Santelli, B., Singer, G. H. S., DiVenere, N., Ginsberg, C., \& Powers, L. E. (1998). Participatory action research: Reflections on critical incidents in a PAR project. Journal of the Association for Persons with Severe Handicaps, 23, 211-222.

Turnbull, A. P. (1985). From professional to parent-A startling experience. In H. R. Turnbull $\&$ A. P. Turnbull (Eds.), Parents speak out. Then and now (2nd ed., pp. 128-129). Columbus, $\mathrm{OH}$ : Merrill.

Turnbull, A. P. (2003). Family quality of life as an outcome of early intervention services: Research and practice directions. In B. F. Williams (Ed..), Directions in early intervention and assessment (pp. 477-498). Spokane, WA: Spokane Guilds' School and Neuromuscular Center.

Turnbull, A. P., Blue-Banning, M., Behr, S., \& Kerns, G. (1987). Family research and intervention: A value and ethical examination. In P. Dokecki \& R. Zaner (Eds.), Ethics and decision-making for persons with severe handicaps: Toward an ethically relevant research agenda (pp. 119-140). Baltimore: Brookes.

Turnbull, A. P., Marquis, J. G., Hoffman, L., Poston, D., Mannan, H., Wang, M., \& Summers, J. A. (2004). A new tool for assessing family outcomes: Psychometric evaluation of the family quality of life scale. Manuscript submitted for publication.

Turnbull, A. P., \& Summers, J. A. (1987). From parent involvement to family support: Evolution to revolution. In S. M. Pueschel, C. Tingey, J. W. Rynders, A. C. Crocker, \& D. M. Crutcher (Eds.), New perspectives on Down syndrome (pp. 289-306). Baltimore: Brookes.

Turnbull, A. P., \& Turnbull, H. R. (2001a). Families, professionals, and exceptionality: Collaborating for empowerment (4th ed.). Upper Saddle River, NJ: Merrill/Prentice Hall.

Turnbull, A. P., \& Turnbull, H. R. (2001b). Selfdetermination for individuals with significant cognitive disabilities and their families. Journal of Association for Persons with Severe Handicaps, 26, 56-62.

Turnbull, A. P., Turnbull, H. R., Soodak, L., \& Erwin, E. (in press). Families, professionals, and exceptionality (5th ed.). Upper Saddle River, NJ: Merrill/Prentice Hall.

Wang, M., Turnbull, A. P., Summers, J. A., Little, T. D., Poston, D. J., Mannan, H., \& Turnbull, R. (in press). Severity of disability and income as predictors of parents' satisfaction with their family quality of life during early childhood years. Research and Practice for Persons with Severe Disabilities.

Wehmeyer, M. L. (2002). Teaching students with mental retardation: Providing access to the general curriculum. Baltimore: Brookes.

Wehmeyer, M. L., \& Palmer, S. B. (2000). Promoting the acquisition and development of self-determination in young children with dis- 
abilities. Early Education and Development, 4, 465-481.

Wehmeyer, M. L., \& Schwartz, M. (1998). The relationship between self-determination, quality of life, and life satisfaction for adults with mental retardation. Education and Training in Mental Retardation and Developmental Disabilities, 33(3), 3-12.

\section{Author:}

Ann P. Turnbull, EdD, Co-Director, Beach Center on Disability, Professor, Department of Special Education, University of Kansas, 1200 Sunnyside Ave., 3111 Haworth Hall, Lawrence, KS 66045. E-mail: turnbull@ukans.edu

\section{Psychotherapy for Persons With Mental Retardation}

\section{Christopher Lynch}

Throughout the previous century, clinicians who have conducted psychotherapy for individuals with mental retardation have lamented over the lack of attention traditionally given to this field. As early as 1936, Chidester and Menninger stated, "Mental retardation has long been looked upon as an organic condition therapeutically hopeless" (p. 616). By the early 1950s, however, there seems to have been a growing body of work demonstrating positive results in this area. These results may have been partly due to a shift in focus with regard to the goals of psychotherapy. As Neham (1951) noted in a review, therapeutic goals had shifted from trying to cure mental retardation to helping individuals cope with their inherent limitations and frustrations. Clinicians continued to provide psychotherapy for individuals with mental retardation from the 1950s to the 1980s. However, the amount of material being published by researchers in this field was scant, and mental health clinicians, by and large, continued to neglect this area of practice. In 1982, Reiss, Levitan, and McNally stated that "Mentally retarded people may constitute one of the most underserved populations in the United States" (p. 361). These authors went on to make the case that psychotherapeutic services for individuals with mental retardation need to be made more available, especially in light of the deinstitutionalization movement.

Although still underserved, the situation has improved since the 1980s. The literature base has grown significantly during the past 20 years. First, articles on the topic have been published in journals both within and beyond the field of developmental disabilities, and a growing number of books focused on this topic are a healthy sign of the field's development (e.g., Blotzer \& Ruth, 1995; Fletcher, 2000; Sinason, 1992). Second, workshops, seminars, and other types of trainings are more readily available. The growth of NADD, an association for persons with developmental disabilities and mental health needs, has been particularly instrumental in this regard. Third, there has been a growth in mental health programs in general for persons with mental retardation. In addition to the provision of direct services, some program administrators seek to foster links and collaboration between mental health providers and agencies that serve individuals with mental retardation (e.g., Beasley, Kroll, \& Sovner, 1992; Carlsson, 2000).

An overview on psychotherapy as applied to persons with mental retardation has not been addressed in this journal since 1984 (Matson). An updated overview is warranted to incorporate some of the developments that have occurred in the field since that time. The following article is intended to cover some of the more salient concepts and practices in this area, including referral, theoretical, conceptual, and ethical issues as well as current concerns.

\section{Referral Issues}

As with the population at large, persons with mental retardation are referred for and seek out psychotherapy for a wide variety of reasons. Data are lacking regarding the specific number and type of referrals psychotherapists treat. However, demographic trends and changes within the field of mental retardation have broadened the range of prob- 
lem areas that psychotherapy can address, including addressing aging-related needs, assisting with transition to community living, addressing increased exposure to the "freedoms and dangers of society," and treating individuals with severe or profound mental retardation.

Demographic changes and increased longevity have contributed to a larger number of individuals with mental retardation who have aging-related needs. These trends have placed a strain on many service delivery systems (Braddock, 1999). An aging population has several implications for the field of psychotherapy. There are a variety of issues that many individuals, including those with mental retardation, have to cope with as they age. Retirement, changing roles in society, bereavement (Good \& Lynch, 1999; Hollins, 1995; Luchterhand \& Murphy, 1998), vulnerability to mental illness (Menolascino \& Fleisher, 1993), and loss of physi$\mathrm{cal} /$ sensory abilities are some issues that psychotherapists may help to address.

The movement of persons with mental retardation from large state facilities to community placements is a trend that began around 1960 and is ongoing (Lakin, Prouty, Polister, \& Anderson, 2000). Such a move is a substantial transition that often requires a person to adjust to many changes simultaneously, which can be stressful for someone who is unprepared to cope with the challenges of community living (Reiss et al., 1982). Even within community settings, persons with mental retardation often have to adapt to new situations and role expectations due to increased efforts at community integration. Although integration is a highly valued principle, adapting to new situations that arise from more independence may result in significant stress (Butz, Bowling, \& Bliss, 2000). Psychotherapists can play a role in helping individuals meet the challenges of community placement and community integration.

As individuals with mental retardation are integrated into society, they become exposed to the same freedoms and dangers as the general population encounters. Such freedoms and dangers may result in circumstances that warrant mental health services, for example, for victims of sexual abuse (e.g., Mansell, 2002; Razza \& Tomasulo, 1996), those who have committed sexual offenses (e.g., Cox-Lindenbaum, 2000; Haaven, Little, \& PetreMiller, 1990), are having problems with substance abuse (e.g., Harris \& Edwardson, 1999; Mayer,
2001), or need help with suicidal ideation (e.g., Kirchner \& Mueth, 2000).

Within recent years, some attention has been given to applying psychotherapeutic principles to individuals with severe/profound mental retardation. Gaedt (1995) and Sinason (1992), for example, have applied and described psychodynamic principles to help understand the behaviors of persons with severe/profound mental retardation and the interactions such individuals have with caregivers. These authors emphasized the need to help caregivers understand how psychological issues impact their interactions with individuals who have severe/profound mental retardation. It will be interesting to see whether demand and interest in this area increase as more persons with severe/profound mental retardation are placed in community settings.

\section{Theoretical and Conceptual Issues}

One can find a variety of theoretical modalities and formats applied to the practice of psychotherapy for persons with mental retardation. Practitioners in the field have drawn from modalities as diverse as psychodynamic (e.g., Carlsson, 2000), cognitive-behavioral (e.g., Hurley \& Sovner, 1991), Jungian (e.g., Baum, 1999), phenomenological (e.g., Blotzer, 2000), and humanistic theories (e.g., Perkins, 1993). In addition to theoretical modalities, clinicians have used formats as diverse as brief (e.g., Anger \& Hawkins, 1999), group (e.g., Tomasulo, 1994), play (e.g., Hellendoorn, 1990), and family (e.g., Lindenbaum, 2000) therapies. Although clinicians may differ in terms of orientation or strategy, there are some theoretical and conceptual issues that can apply across a variety of approaches, including recognizing the need to modify psychotherapy, being cognizant of the impact of having a disabled identity, being attuned to dependency issues, and being aware of the frequent need to involve others in the treatment process.

Although practitioners in the field firmly believe in the value of psychotherapy, they do acknowledge the need for modification to address cognitive, developmental, and speech/language deficits (e.g., Butz et al., 2000; Hurley, Pfadt, Tomasulo, \& Gardner, 1996; Levitas \& Gilson, 2000a; Mansell, 2002; Tallant \& Johnson-Burnham, 2000; Yepsen, 1952). Suggested modifications include simplifying language, presenting information at a slower rate, checking for comprehension of concepts, repeating 
concepts, using concrete language, structuring therapy sessions, minimizing distractions, shortening length of sessions, using a directive approach, involving caregivers to increase generalization of skills, making concepts relevant to recent real-life situations, allowing more time for verbal responses, using nonverbal communication, being more goal focused, using visual materials, and employing roleplaying methods to bolster learning. Not all psychotherapy clients will require the same modifications. An individualized assessment can help determine an individual's strengths and deficits and the required modifications (Lynch, 2000).

Having a "disabled" or "mentally retarded" identity can have a substantial impact on an individual (Aman, 1991; Sinason, 1992), which can result in emotional pain. An individual may develop a variety of unhealthy defenses and strategies to avoid confronting such pain. In this vein, Sinason (1992) referred to the defensive exaggerations that develop in reaction to having a disability as a "secondary handicap" (or disability). Psychotherapists are not immune to negative thoughts, feelings, or attitudes regarding mental retardation. As Blotzer (2000) noted, "Mental retardation evokes strong reactions and defenses against these reactions. Sometimes we are repulsed by a client's appearance, mannerisms, or poor hygiene" (p. 96). Along with Levitas and Gilson (2000b), she highlighted the value of acknowledging these negative thoughts, feelings, and attitudes when conducting psychotherapy with this population.

Although dependency issues may be relevant for any psychotherapy client, it is particularly important when working with persons who have mental retardation. These individuals tend to present with a trait termed outerdirectedness (MacMillan \& Wright, 1974; Zigler, Bennett-Gates, Hodapp, \& Henrich, 2002), which refers to a tendency to look to others for cues to solutions of difficult or ambiguous problems. Another useful concept is Levitas and Gilson's (1990) mediated self, which refers to the tendency of these individuals to rely on the cognitive functioning of others-particularly during times of stress. Psychotherapy can help to counteract these dependent tendencies and help a person (and caregivers) develop a healthy balance between the need for autonomy and the need for support.

For the general population, psychotherapy is usually an intensely private undertaking. With the exception of marital and family therapy, a psychotherapist's only source of information and means of influence is the client. In the field of developmental disabilities, however, a number of individuals may become involved in the therapy process. Clinicians may need to involve others in the psychotherapy process for a variety of reasons. For example, communication with others is often necessary to gauge progress, implement treatment strategies, assist with appropriate goal setting, and increase awareness of salient mental health issues.

\section{Ethical Issues}

Although the standard ethical guidelines and practices for psychotherapists apply to all clients, there are three particular areas of concern when a client has mental retardation: (a) obtaining full and voluntary consent for treatment, (b) developing treatment goals that incorporate the client's input and preferences, and (c) maintaining confidentiality.

It is sometimes difficult to determine whether full and voluntary consent for treatment has been obtained before psychotherapy is initiated for an individual with mental retardation. Although data are lacking, clinical experience dictates that it is often an agency or caretaker that refers the prospective client for treatment. Persons with mental retardation have a tendency to acquiesce in interview-like situations for a variety of reasons (e.g., Finlay $\&$ Lyons, 2002; Sigelman, Budd, Spanhel, \& Schoenrock, 1981). Consequently, they may give consent for treatment even though they do not really want to or do not fully understand what treatment entails. In other cases, the individual may be referred under significant pressure. For example, I have experienced some circumstances under which clients were told that they had to undergo psychotherapy if they want to remain in their current work or residential setting. Under such circumstances, consent cannot be considered full or voluntary.

Related to consent for treatment is the setting of therapeutic goals in an ethically acceptable manner. The determination of treatment goals may be influenced by the needs of the referring agency or caregiver. Although there are no specific data on this issue, clinical experience dictates that a referral is often made for psychotherapy because the agency or caregiver is seeking to eliminate a disruptive or undesirable behavior(s). The client's preference, however, may be to develop autonomy and independence rather than eliminating specific behaviors. In addition, persons with mental retardation may be more passive with regard to allowing others 
to set goals for them and may view the therapist as someone who will tell them what to do without any input on their part (Levitas \& Gilson, 2000a). Being aware of these issues can help psychotherapists develop treatment goals in a collaborative manner that incorporates the client's preferences and input.

As noted above, a variety of individuals may become involved in the treatment of a person with mental retardation. As such, this can lead to dilemmas centered on the issue of confidentiality. In my own experience, caregivers often assume that they can inquire about any aspect of the therapy process without seeking the consent of the client. In addition, psychotherapists may regularly be asked to present sensitive information in team meetings. Once a psychotherapist provides sensitive information, he or she has little control over how that information will be shared or used. Thus, for example, a clinician may obtain full consent from a client to release information at a staff meeting; however, neither the clinician nor the client can be certain where that information will go or how it will be used once the meeting is over.

There are many other issues and dilemmas that may arise from working with persons with mental retardation (e.g., when treating several people who live in the same residence). In all cases, a psychotherapist must consider each aspect of a situation when deciding how to resolve an ethical dilemma. Clarifying roles and expectations as early as possible can help prevent ethical dilemmas. Often, families and service providers need to be educated with regard to the psychotherapy process and the importance of such issues as confidentiality. Keller (2000), for example, suggested preparing a fact sheet about psychotherapy to give to family members and service providers. Psychotherapy clients may also benefit from education with regard to the psychotherapy process. Such education facilitates active participation in goal setting.

\section{Current Concerns}

There have been monumental changes in health care over the past 2 decades that have significantly impacted the practice of psychotherapy. Fiscal concerns that have been affecting the field of psychotherapy as a whole are becoming increasingly relevant to the field of mental retardation, including the impact of managed-care plans; increasing restrictions on government-funded insurance programs, such as Medicaid/Medicare; and the struggle for mental health parity. As a result of changes in health care spending, psychotherapists have been pressured to provide short-term treatment that is relatively limited in scope. Although such strategies may be effective for some individuals with mental retardation, this is not always the case. Because of cognitive deficits, these individuals may need more time to learn and incorporate coping strategies. They may also require "booster" sessions (e.g., monthly, bimonthly) after the initial trial of psychotherapy to review therapeutic principles and techniques and their application to novel situations. In addition, providing psychotherapy for persons with mental retardation often involves the use of indirect services (e.g., observation, participation on team meetings, consultation with agencies and caregivers). Such services are not typically reimbursed in the current cost-cutting environment.

Although the notion that psychotherapy can be effective for individuals with mental retardation has been increasingly accepted, concerns have been expressed regarding the lack of empirically sound research (Butz et al., 2000; Prout, Chard, NowakDrabik, \& Johnson, 2000). A large systematic review of effectiveness studies has recently been conducted by Prout and Nowak-Drabik (2003). They looked at 92 studies, covering the 1968-1998 period, in which researchers examined the effectiveness of psychotherapy. They concluded from their review that psychotherapy is "moderately" effective for individuals with mental retardation and yields a "moderate" amount of change for this group. However, they acknowledged that many of the studies were poor in terms of methodological rigor and design (e.g., based upon single-subject designs and case studies, poorly described interventions, vaguely described outcome data).

In conclusion, psychotherapeutic approaches have been applied to persons with mental retardation since the beginning of the previous century. The work in this area, however, was relatively scant and the field lacked cohesiveness. Within the past 20 years, however, significant development has occurred. The literature base has grown substantially and a greater sense of cohesiveness has been obtained through conferences, trainings, and the efforts of professional organizations. Efforts have also been made to improve mental health treatment in general for persons with mental retardation. Psychotherapy has been an important part of these efforts. However, there are some current concerns that the field will need to address in order to maintain its growth and vibrancy. Two primary areas in- 
clude examining the fiscal constraints that have been affecting the field of psychotherapy as a whole and demonstrating the effectiveness of psychotherapy for individuals with mental retardation through empirically rigorous research.

\section{References}

Aman, M. G. (1991). Assessing psychopathology and behavior problems in persons with mental retardation: A review of available instruments. Rockville, MD: U.S. Department of Health and Human Services.

Anger, K., \& Hawkins, J. (1999). A brief therapy approach to working with the problems of individuals with dual diagnoses and their families. In R. J. Fletcher, D. Griffiths, \& D. NagyMcNelis (Eds.), Proceedings of the NADD 16th annual conference (pp. 47-48). Kingston, NY: NADD Press.

Baum, N. T. (1999). Improving the quality of life of people with dual diagnosis through the use of an expressive, psychodynamic Jungian psychotherapy. In R. J. Fletcher, D. Griffiths, \& D. Nagy-McNelis (Eds.), Proceedings of the NADD 16th annual conference (pp. 43-46). Kingston, NY: NADD Press.

Beasley, J. B., Kroll, J., \& Sovner, R. (1992). Community-based crisis mental health services for persons with developmental disabilities: The Start model. Habilitative Mental Healthcare Newsletter, 11(9), 55-57

Blotzer, M. A. (2000). The egocentric error. In R. J. Fletcher (Ed.), Therapy approaches for persons with mental retardation (pp. 87-98). Kingston, NY: NADD Press.

Blotzer, M. A., \& Ruth, R. (1995). Sometimes you just want to feel like a human being: Case studies of empowering psychotherapy with people with disabilities. Baltimore: Brookes.

Braddock, D. (1999). Aging and developmental disabilities: Demographic and policy issues affecting American families. Mental Retardation, 37, 155-161.

Butz, M. R., Bowling, J. B., \& Bliss, C. A. (2000). Psychotherapy with the mentally retarded: A review of the literature and the implications. Professional Psychology: Research and Practice, 31, 42-47.

Carlsson, B. (2000). Psychoanalytic psychotherapy with intellectually disabled adults-Evaluation by using projective tests: A collaboration project between a psychiatric clinic and the ser- vices for mentally handicapped. NADD Bulletin, 3(5), 88-92.

Chidester, L., \& Menninger, K. A. (1936). The application of psychoanalytic methods to the study of mental retardation. American Journal of Orthopsychiatry, 6, 616-625.

Cox-Lindenbaum, D. (2000). Psychotherapy for sex offenders with developmental disabilities. In R. J. Fletcher (Ed.), Therapy approaches for persons with mental retardation (pp. 151-169). Kingston, NY: NADD Press.

Finlay, W. M. L., \& Lyons, E. (2002). Acquiescence in interviews with people who have mental retardation. Mental Retardation, 40, 14-29.

Fletcher, R. J. (Ed). (2000). Therapy approaches for persons with mental retardation. Kingston, NY: NADD Press.

Gaedt, C. (1995). Psychotherapeutic approaches in the treatment of mental illness and behavioral disorders in mentally retarded people: The significance of a psychoanalytic perspective. Journal of Intellectual Disability Research, 39, 233239.

Good, J., \& Lynch, C. (1999). Challenges in addressing bereavement. In R. J. Fletcher, D. Griffiths, \& D. Nagy-McNelis (Eds.), Proceedings of the NADD 16th annual conference (pp. 12-14). Kingston, NY: NADD Press.

Haaven, J., Little, R., \& Petre-Miller, D. (1990). Treating intellectually disabled sex offenders. Orwell, VT: Safer Society Press.

Harris, M., \& Edwardson, R. (1999). "3D” unified group process for the treatment of triply diagnosed persons. In R. J. Fletcher, D. Griffiths, \& D. Nagy-McNelis (Eds.), Proceedings of the NADD 16th annual conference (pp. 28-30). Kingston, NY: NADD Press.

Hellendoorn, J. (1990). Indications and goals for play therapy with the mentally retarded. In A. Dorsen, A. Van Gennep, \& G. J. Zwanikken (Eds.), Treatment of mental illness and behavioral disorders in the mentally retarded (pp. 179-188). Leiden, The Netherlands: Logon.

Hollins, S. (1995). Managing grief better: People with developmental disabilities. Habilitative Mental Healthcare Newsletter, 14(3), 50-52.

Hurley, A. D., Pfadt, A., Tomasulo, D., \& Gardner, W. I. (1996). Counseling and psychotherapy. In J. W. Jacobson \& J. A. Mulick (Eds.), Manual of diagnosis and professional practice in mental retardation (pp. 371-380). Washington, DC: American Psychological Association.

Hurley, A. D., \& Sovner, R. (1991). Cognitive behavioral therapy for depression in individuals 
with developmental disabilities. Habilitative Mental Healthcare Newsletter, 10, 41-47.

Keller, E. M. (2000). Points of intervention: Facilitating the process of psychotherapy with people who have developmental disabilities. In R. J. Fletcher (Ed.), Therapy approaches for persons with mental retardation (pp. 27-47). Kingston, NY: NADD Press.

Kirchner, L., \& Mueth, M. (2000). Suicide in individuals with developmental disabilities. In $\mathrm{R}$. J. Fletcher (Ed.), Therapy approaches for persons with mental retardation (pp. 127-150). Kingston, NY: NADD Press.

Lakin, K. C., Prouty, R., Polister, B., \& Anderson, L. (2000). Over three quarters of all residential service recipients in community settings as of June 1999. Mental Retardation, 38, 378-379.

Levitas, A. S., \& Gilson, S. F. (1990). Toward the developmental understanding of the impact of mental retardation on assessment of psychopathology. In E. Dibble \& D. G. Gray (Eds.), Assessment of behavior problems in persons with mental retardation living in the community (pp. 71-106). Rockville, MD: National Institute of Mental Health.

Levitas, A. S., \& Gilson, S. F. (2000a). Individual psychotherapy for persons with mild and moderate mental retardation. In T. McNelis, B. Barol, M. Fleisher, R. J. Fletcher, D. Nagy, \& H. T. Prout (Eds.), Proceedings of the NADD International Congress IV (pp. 51-57). Kingston, NY: NADD Press.

Levitas, A. S., \& Gilson, S. F. (2000b). Transference/countertransference in individual psychotherapy. In R. J. Fletcher (Ed.), Therapy approaches for persons with mental retardation (pp. 49-64). Kingston, NY: NADD Press.

Lindenbaum, L. (2000). Family therapy: Supporting parents of a young adult with dual diagnosis during the transition to adulthood. In R. J. Fletcher (Ed.), Therapy approaches for persons with mental retardation (pp. 113-126). Kingston, NY: NADD Press.

Luchterhand, C., \& Murphy, N. (1998). Helping adults with mental retardation grieve a death loss. Bristol, PA: Accelerated Development.

Lynch, C. (2000). Modifying psychotherapy for individuals with mental retardation. NADD Bulletin, 3(5), 85-87.

MacMillan, D., \& Wright, D. (1974). Outerdirectedness in children of three ages as a function of experimentally induced success and failure. Journal of Educational Psychology, 68, 136-148.

Mansell, S. (2002). Providing therapy services to people who have been sexually abused. NADD Bulletin, 5(3), 43-48.

Matson, J. L. (1984). Psychotherapy with persons who are mentally retarded. Mental Retardation, 22, 170-175.

Mayer, M. A. (2001). SAMIRIS: Substance abusers who have both mental illness and mental retardation. NADD Bulletin, 4(5), 92-98.

Menolascino, F. J., \& Fleisher, M. H. (1993). Mental health care in persons with mental retardation: Past, present, and future. In R. J. Fletcher \& A. Dosen (Eds.), Mental health aspects of mental disorders: Progress in assessment and treatment (pp. 18-41). New York: Lexington.

Neham, S. (1951). Psychotherapy in relation to mental deficiency. American Journal of Mental Deficiency, 55, 557-572.

Perkins, D. M. (1993). The use of counseling and psychotherapy with dually diagnosed persons. NADD Newsletter, 10(4), 1-7.

Prout, H. T., Chard, K. M., Nowak-Drabik, K. M., \& Johnson, D. M. (2000). Determining the effectiveness of psychotherapy with persons with mental retardation: The need to move toward empirically based research. NADD Bulletin, 3(6), 83-86.

Prout, H. T., \& Nowak-Drabik, K. M. (2003). Psychotherapy with persons who have mental retardation: An evaluation of effectiveness. American Journal on Mental Retardation, 108, 82-93.

Razza, N., \& Tomasulo, D. J. (1996). The sexual abuse continuum: Therapeutic intervention with individuals with mental retardation. Habilitative Mental Healthcare Newsletter, 15, 1922.

Reiss, S., Levitan, G. W., \& McNally, R. J. (1982). Emotionally disturbed mentally retarded people. American Psychologist, 37, 361-367.

Sigelman, C. K., Budd, E. C., Spanhel, C. L., \& Schoenrock, C. J. (1981). When in doubt say yes: Acquiescence in interviews with mentally retarded persons. Mental Retardation, 19, 5358.

Sinason, V. (1992). Mental handicap and the human condition: New approaches from the Tavistock. London: Free Associated Books.

Tallant, B., \& Johnston-Burnham, M. (2000). Community agency collaboration for specialized treatment of dually diagnosed children: A model program. NADD Bulletin, 3(5), 93-95.

Tomasulo, D. J. (1994). Action techniques in group counseling: The double. Habilitative Mental Healthcare Newsletter, 13, 41-45. 
Yepsen, L. N. (1952). Counseling the mentally retarded. American Journal of Mental Deficiency, 57, 205-213.

Zigler, E., Bennett-Gates, D., Hodapp, R., \& Henrich, C. C. (2002). Assessing personality traits of individuals with mental retardation. American Journal on Mental Retardation, 107, 181193.
The completion of this article was made possible by the support of two organizations: Developmental Disabilities Center- Mountainside Hospital and The Brothers of Charity-Ireland, 4 Anglesea St., Clonmel County Ipperary Ireland.

Author:

Christopher Lynch, PhD, Principal Psychologist, Developmental Disabilities Center, Brothers of Charity, Mountainside Hospital, Montclair, NJ 07042-4837. E-mail: lynches@iol.ie

\section{Importance of Training and Expertise to Assess "What Works" for Individuals With Intellectual Disabilities}

\section{Joan B. Beasley}

Thank you for publishing Beail's (2003) perspective on what works for people with mental retardation. Beail made valid arguments for both his conclusion that the absence of evidence in support of cognitive behavior therapy does not necessarily indicate that it is an ineffective approach and in his advocacy for a full range of mental health treatment for people with mental retardation and mental health needs.

There was, however, an essential factor absent from Beail's (2003) discussion, namely, that the unique presentation of many people with intellectual disabilities often requires special clinical skills in both diagnosis and treatment (Bouras, Kon, \& Drummond, 1993; Bregman, 1991; Campbell \& Malone, 1991; Criscione, Kastner, Walsh, \& Nathanson, 1993; Dosen, 1988; Evangelista, 1988; Hurley, 1996; Jacobson, 1990; Sovner, 1986). This does not necessarily indicate that individuals with intellectual disabilities cannot benefit from most treatment methods. Rather, clinicians providing treatment must have the training and ability to provide care in the context of the person's intellectual capabilities.

Unfortunately, most mental health professionals who treat individuals with intellectual disabilities have had little to no training in applying their specific treatment modality to people with co-occurring intellectual disabilities and mental health needs. The dearth of both formalized training approaches and training opportunities for clinicians in the provision of psychotherapy for individuals with intellectual disabilities most likely negatively affects treatment outcomes and should be considered an obstacle to accurately test the benefits of specific treatment modalities.

\section{References}

Beail, N. (2003). What works for people with mental retardation? Critical commentary on cognitivebehavioral and psychodynamic psychotherapy research. Mental Retardation, 41, 468-471.

Bouras, N., Kon, Y., \& Drummond, C. (1993). Medical and psychiatric needs of adults with a mental handicap. Journal of Intellectual Disability Research, 37, 177-182.

Bregman, J. D. (1991). Current developments in the understanding of mental retardation Part II: Psychopathology. Journal of the American Academy of Child and Adolescent Psychiatry, 30, 861-872.

Campbell, M., \& Malone, R. (1991). Mental retardation and psychiatric disorders. Hospital and Community Psychiatry, 42, 374-379.

Dosen, A. (1993). Diagnosis and treatment of psychiatric and behavioral disorders in mentally retarded individuals: The state of the art. Journal of Intellectual Disability Research, 37, 1-7.

Evangelista, L. A. (1988). Comprehensive management of the mentally retarded/mentally ill. In J. Stark, F. Menolascino, M. Albarelli, \& V. Gray (Eds.), Mental retardation and mental health: Classification, diagnosis, treatment services (pp. 140-146). New York: SpringerVerlag. 
Hurley, A. D. (1996). Vocational rehabilitation approaches to support adults with mental retardation. Habilitative Mental Healthcare Newsletter, 15, 29-33.

Jacobson, J. W. (1990). Assessing the prevalence of psychiatric disorders in the developmentally disabled population. In E. Dibble \& D. Gray (Eds.), Assessment of persons with mental retardation living in the community (pp. 19-70). Rockville, MD: National Institute of Mental Health.
Sovner, R. (1986). Limiting factors in the use of DSMIII criteria with mentally ill/ mentally retarded persons. Psychopharmacology Bulletin, 22, 1055-1059.

Author:

Joan B. Beasley, PhD, Consultation and Training Services, 184 Bonad Rd., Chestnut Hill, MA 02467. E-mail: jbbeasley@rcn.com

This research was supported by a grant from the National Institute on Disability and Rehabilitation Research to the Beach Center on Disability, Grant \#H133B031133. 